\title{
Do drug treatment variables predict cognitive performance in multidrug-treated opioid-dependent patients? A regression analysis study
}

Pekka Rapeli ${ }^{1,2,3^{*}}$, Carola Fabritius ${ }^{2}$, Hely Kalska ${ }^{3}$ and Hannu Alho ${ }^{2,4}$

\begin{abstract}
Background: Cognitive deficits and multiple psychoactive drug regimens are both common in patients treated for opioid-dependence. Therefore, we examined whether the cognitive performance of patients in opioid-substitution treatment (OST) is associated with their drug treatment variables.

Methods: Opioid-dependent patients $(N=104)$ who were treated either with buprenorphine or methadone ( $n=52$ in both groups) were given attention, working memory, verbal, and visual memory tests after they had been a minimum of six months in treatment. Group-wise results were analysed by analysis of variance. Predictors of cognitive performance were examined by hierarchical regression analysis.

Results: Buprenorphine-treated patients performed statistically significantly better in a simple reaction time test than methadone-treated ones. No other significant differences between groups in cognitive performance were found. In each OST drug group, approximately $10 \%$ of the attention performance could be predicted by drug treatment variables. Use of benzodiazepine medication predicted about 10\% of performance variance in working memory. Treatment with more than one other psychoactive drug (than opioid or BZD) and frequent substance abuse during the past month predicted about $20 \%$ of verbal memory performance.

Conclusions: Although this study does not prove a causal relationship between multiple prescription drug use and poor cognitive functioning, the results are relevant for psychosocial recovery, vocational rehabilitation, and psychological treatment of OST patients. Especially for patients with BZD treatment, other treatment options should be actively sought.
\end{abstract}

Keywords: Opioid-dependence, Opioid agonist therapy, Pharmacotherapy, Psychotropic drugs, Neurocognitive performance, Neuropsychological testing

\section{Background}

Opioid abuse affects about $0.4 \%$ of the world's population in the age range of 15-64 years [1]. Many of them are dependent on opioids and fail to complete opioid withdrawal. Standard treatment for these individuals is opioid substitution treatment (OST), also known as opioid maintenance treatment. However, opioid-dependence

\footnotetext{
* Correspondence: pekka.rapeli@hus.fi

${ }^{1}$ Unit for Drug Dependence. Department of Psychiatry, Helsinki University

Central Hospital, Helsinki, Finland

${ }^{2}$ Department of Mental Health and Substance Abuse Services, National

Institute for Health and Welfare (THL), Helsinki, Finland

Full list of author information is available at the end of the article
}

is often complicated with psychiatric comorbidity. In epidemiological studies, the joint lifetime prevalence of opioid dependence and non-substance-use psychiatric disorders has ranged from almost $50 \%$ up to $90 \%$, while the current prevalence of mood, anxiety, or personality disorders is also high [2-4]. Consequently, polypharmacy with psychoactive medication is a common practice in OST [5-9]. While several studies have examined the cognitive performance differences between buprenorphinevs. methadone-treated opioid-dependent patients [10-14], few studies have examined the possible role of other psychoactive medications on the cognitive functioning of

\section{Biomed Central}


these patients. Thus, the results of current studies may not be fully appropriate for multidrug-treated patients. However, studies concentrating on this patient group would be important because opioid-dependent patients who are treated with multiple drugs tend to have lower quality of life than those who only use an opioid agonist drug [15]. A recent study concerning cannabisdependent individuals found that even relatively subtle cognitive deficits that were seen in test performance can be verified by those who know the affected individual well [16]. Furthermore, at least for BZDs, even prescription drug use has been shown to be associated with serious health and safety risks $[17,18]$. Thus, if a drug treatment variable is negatively associated with cognitive performance in OST patients this may have practical relevance.

Earlier we have reported that opioid-dependent patients treated with buprenorphine/naloxone along with BZDs do not show attention deficit as measured by reaction time tasks, but their working memory and verbal memory performance is worse than that of healthy controls, at least for the first six months in treatment [19]. Patients treated with methadone along with BZDs show deficits in attention, working memory, and verbal memory. In our later study, OST drug group membership (buprenorphine vs. methadone) correlated significantly with attention performance and improvement in the Letter-Number Sequencing. Recent high-frequency substance abuse was associated with poor performance in working memory. Although the effects of the other two highest correlates were controlled for, many other variables could not be taken into account.

Our major aim in the current study was to examine the predictive power of drug treatment variables on specific cognitive performance measures in a naturalistic sample of multidrug-treated opioid-dependent patients. There is some evidence that short-term use of high dose methadone and BZD diazepam affects negatively on simple reaction times in opioid-dependent patients, but in buprenorphine patients only high diazepam dose affects negatively on reaction times [20,21]. Therefore, we hypothesized that in buprenorphine patients, BZD treatment (use vs. non-use or dose) but not buprenorphine treatment variables (dose) would be negatively associated with attention performance; while in methadone patients both methadone and BZD treatment variables would affect negatively on attention performance as measured by reaction times. There is preliminary evidence that buprenorphine may preserve working memory performance better than methadone [22,23]. Thus, we hypothesized that having buprenorphine as the OST drug would predict good working memory performance among opioid-dependent patients. It has been shown that longterm use of BZD drugs is associated with a wide range of cognitive deficits [24]. Sedative and anticholinergic effects have been reported for various psychiatric drugs $[25,26]$. Consequently, patients treated with several psychoactive drugs typically perform worse in cognitive tests than patients treated with a single drug $[27,28]$. We therefore hypothesized that being on a BZD drug or on a high number of prescribed psychoactive drugs (other than opioid or BZD) would predict poor cognitive performance in all measures among opioid-dependent patients treated with buprenorphine or methadone.

\section{Methods}

The study participants were volunteer opioid-dependent patients admitted for OST in the addiction clinics of the greater Helsinki or Tampere area. Further inclusion criteria were the following: aged 18-50 years, native Finnish speaker, opioid-dependence diagnosis, and minimum six months in OST with methadone, buprenorphine, or buprenorphine/naloxone. Exclusion criteria were the following: uncontrolled polysubstance abuse, acute alcohol abuse, or acute axis I psychiatric disorder (e.g. acute phase of major depression, suicidality, hypomania, mania, or psychosis), initiation of new psychoactive drugs within the past week, severe brain injury, chronic neurological disease, history of other than substance-induced psychoses, epileptic seizures, human immunodeficiency virus (HIV) infection, pregnancy, or primary cognitive deficit (estimated IQ less than 85). To ensure study eligibility, the clinical psychiatric interview SCID I was conducted for each participant, and diagnostic criteria from the Diagnostic and Statistical Manual of Mental Disorders (DSM-IV) were applied [29]. Estimation of IQ was done by the neuropsychologist and it was based on the vocabulary subtest of the Wechsler Adult Intelligence Scale - Revised (WAIS-R) [30].

Each participant was screened for substance abuse by urine sample on the day of testing and at least once in the preceding month using the Nano5 test (from Ferle Produkter AB; Helsingborg, Sweden). Participants showing signs of current intoxication or binging on any substance of abuse and those having extra psychoactive drug doses within the last $24 \mathrm{~h}$ were all excluded. Also, those showing a positive drug screen for non-prescribed opioids or BZDs were excluded. The study included 104 OST patients, with $29 \%$ of them coming from the longitudinal sample used in the previous studies [5,13]. The rest were new long-term treated opioid-dependent patients. As shown in Table 1, buprenorphine-treated patients were statistically significantly younger than methadone ones, otherwise there were no significant demographic differences between buprenorphine- vs. methadone-treated patients.

The study was approved by both the independent Ethical Committee of the Hospital District of Helsinki and Uusimaa (permission 90/2001) and the A-Clinic 
Table 1 Group demographics

\begin{tabular}{|c|c|c|c|}
\hline & $\begin{array}{l}\text { Buprenorphine } \\
(n=52)\end{array}$ & $\begin{array}{l}\text { Methadone } \\
(\mathrm{n}=52)\end{array}$ & $\begin{array}{l}\text { Group } \\
\text { comparisons }^{\mathrm{a}}\end{array}$ \\
\hline Age $(M \pm S D)$ & $31 \pm 7$ & $35 \pm 8$ & $\mathrm{BN}<\mathrm{M}, p=.007^{* *}$ \\
\hline \multirow[t]{2}{*}{ Sex, female/male } & $18 / 34$ & $20 / 32$ & $p=.84$ \\
\hline & $35 \% / 65 \%$ & $38 \% / 62 \%$ & \\
\hline Verbal intelligence $^{\mathrm{b}}(M \pm S D)$ & $100 \pm 10$ & $101 \pm 10$ & $p=.44$ \\
\hline \multirow[t]{2}{*}{ Education, patients with primary education/any secondary education } & $35 / 17$ & $34 / 18$ & $p=1.00$ \\
\hline & $67 \% / 33 \%$ & $65 \% / 35 \%$ & \\
\hline Substance abuse onset age, years $(\mathrm{M} \pm \mathrm{SD})$ & $16 \pm 3$ & $15 \pm 2$ & $p=.17$ \\
\hline \multirow[t]{2}{*}{ Patients with early onset of substance abuse ${ }^{c}$} & 15 & 23 & $p=.31$ \\
\hline & $29 \%$ & $44 \%$ & \\
\hline Duration of OST, months $(M \pm S D)$ & $14 \pm 7$ & $17 \pm 10$ & $p=.08$ \\
\hline \multirow[t]{2}{*}{ Patients with more than 12 month in OST } & 30 & 33 & $p=.69$ \\
\hline & $57 \%$ & $63 \%$ & \\
\hline \multicolumn{4}{|l|}{ Number of cognitive testing } \\
\hline patients with one testing & $34(65 \%)$ & $40(77 \%)$ & $p=.28$ \\
\hline patients with two or three testing & $18(35 \%)$ & $12(23 \%)$ & \\
\hline \multirow[t]{2}{*}{ Patients with high-frequency substance abuse in the previous month ${ }^{d}$} & 18 & 22 & $p=.55$ \\
\hline & $35 \%$ & $42 \%$ & \\
\hline \multirow[t]{2}{*}{ Patients with positive drug screen at test } & 13 & 13 & $p=1.00$ \\
\hline & $25 \%$ & $25 \%$ & \\
\hline \multirow[t]{2}{*}{ Patients with the past month daily nicotine use } & 52 & $51 \%$ & $p=.50$ \\
\hline & $100 \%$ & $98 \%$ & \\
\hline
\end{tabular}

Note. $B N=$ buprenorphine patients, $M=$ methadone patients.

${ }^{a}$ Tested with $t$-test or Fisher's Exact Test.

${ }^{\mathrm{b}}$ Estimation based on the vocabulary subtest of the Wechsler Adult Intelligence Scale - Revised (WAIS-R) [30].

${ }^{c}$ Considered as early up to 14 years of age.

${ }^{\mathrm{d} C o n s i d e r e d ~ a s ~ h i g h ~ w h e n ~ t h r e e ~ o r ~ m o r e ~ d a y s ~ a ~ w e e k . ~ A l c o h o l ~ u s e ~ w a s ~ t a k e n ~ i n t o ~ a c c o u n t ~ i f ~ i t ~ w a s ~ a t ~ l e a s t ~ m e a n ~ w e e k l y ~} 16$ portions ( $12 \mathrm{~g}$ ) for females and

24 portions for males or binge drinking occurred on any day.

${ }^{* *} p<0.01$.

Foundation. The study was conducted in accordance with the 1964 Declaration of Helsinki. All participants were able to read and understand the patient information sheet, and signed the informed consent form. The participants were free to discontinue participation in the study whenever they wanted. They were paid $€ 20$ if they attended all study visits.

\section{Procedure}

The patients were tested with cognitive measures between three to six hours after the administration of the opioid substitution drug. In the buprenorphine group, $54 \%$ of the patients were given buprenorphine/naloxone. Thus, they received a dose of naloxone in the ratio of 1:4 combined with their buprenorphine dose. When the tablet is given sublingually the absorption of naloxone is low and eliminates within the first hours [31]. It has been shown that naloxone has minimal, if any effect, on the bioavailability or pharmacokinetics of buprenorphine $[32,33]$. Therefore, we combined patients using either one of the buprenorphine compounds. Benzodiazepine doses of oxazepam were converted to a diazepam equivalent dose in the ratio of 3:1 [34]. Table 2 describes the psychoactive medications used by the participants in the 24-hour period before the testing. Medication doses were compared by using the Mann-Whitney $U$ test. Medication frequencies were compared using the chisquare test.

\section{Statistical analyses}

Group-wise comparisons of cognitive performance between buprenorphine and methadone patients were done by an analysis of variance (ANOVA). As our verbal and visual memory tests lacked age-corrected norm values and there was a significant difference between the patient groups on age, an analysis of covariance (ANCOVA) was used when testing these parameters. In all group-wise comparisons, the normality assumptions of the cognitive variables were first examined by Shapiro-Wilk's test and the homogeneity of variance by the Levene's test. When appropriate, analyses of the main effects were interpreted using the Welch correction for heterogeneous variances. The data were also screened for outlying values. There was strong positive 
Table 2 Medications given to patients within the last $24 \mathrm{~h}$ before testing in sample I

\begin{tabular}{|c|c|c|c|}
\hline & $\begin{array}{l}\text { Buprenorphine } \\
(n=52)\end{array}$ & $\begin{array}{l}\text { Methadone } \\
(n=52)\end{array}$ & $\begin{array}{l}\text { Group comparison } \\
p \text {-values }\end{array}$ \\
\hline Opioid agonist drug $(M \pm S D)$ & $20 \pm 6 \mathrm{mg}$ & - & - \\
\hline Buprenorphine $(M \pm S D)$ & - & $113 \pm 49 \mathrm{mg}$ & \\
\hline Patients using any psychoactive medication, other than opioid & $42(81 \%)$ & $43(83 \%)$ & $p=1.00$ \\
\hline Patients using any BDZ drug & $37(71 \%)$ & $38(73 \%)$ & $p=1.00$ \\
\hline diazepam & $29(56 \%)$ & $24(46 \%)$ & $p=.43$ \\
\hline oxazepam & $8(15 \%)$ & $14(27 \%)$ & $p=.15$ \\
\hline Benzodiazepine, diazepam equivalent dose $(M \pm S D)$ & $22 \pm 10 \mathrm{mg}$ & $21 \pm 10 \mathrm{mg}$ & $p=0.77$ \\
\hline \multicolumn{4}{|l|}{ The number psychoactive drugs, other than opioid or BZD ${ }^{a}$} \\
\hline$(M \pm S D)$ & $1.2 \pm 1.2$ & $1.2 \pm 1.2$ & $p=.81$ \\
\hline 0, no. patients (\%) & $18(35 \%)$ & $19(36 \%)$ & $p=1.00$ \\
\hline 1 no. patients (\%) & 19 (37\%) & $13(25 \%)$ & $p=.29$ \\
\hline 2 no. patients (\%) & $9(17 \%)$ & $13(25 \%)$ & $p=.47$ \\
\hline 3 no. patients (\%) & $2(4 \%)$ & $5(10 \%)$ & $p=.44$ \\
\hline 4 or more no. patients (\%) & $4(7 \%)$ & $2(4 \%)$ & $p=.68$ \\
\hline \multicolumn{4}{|l|}{ Patients using psychoactive drug, other than opioid or BZD } \\
\hline Any drug ${ }^{b}$ & $34(65 \%)$ & $33(63 \%)$ & $p=1.00$ \\
\hline Anticonvulsants & $6(12 \%)$ & $5(10 \%)$ & $p=1.00$ \\
\hline Antidepressants & $22(42 \%)$ & $13(25 \%)$ & $p=.096$ \\
\hline Antihistamines & $6(12 \%)$ & $10(19 \%)$ & $p=.42$ \\
\hline Neuroleptics & $7(13 \%)$ & $9(17 \%)$ & $p=.79$ \\
\hline Non-Benzodiazepine hypnotics & $16(31 \%)$ & $19(37 \%)$ & $p=.68$ \\
\hline Non-opioid pain killers & $4(8 \%)$ & $6(12 \%)$ & $p=.74$ \\
\hline
\end{tabular}

Tested with $t$-test or Fisher's Exact Test.

${ }^{\mathrm{b}}$ These included anticonvulsants (used as mood stabilizers), antidepressants, neuroleptics (used with anxiolytic indications), non-benzodiazepine hypnotics, and non-opioid pain killers.

correlation (.78) between the alertness task conditions; hence in order to reduce the number of dependent variables in the regression analysis, these measures were combined by standardizing the values and pooling them.

The assumption of a linear relationship between the dependent variable and predictors was checked by plotting the data (LOWESS curves) and by a lack of fit test. In order to ascertain the linearity between the dependent variable and predictors, many of the predictors were transformed into dichotomous ordinal variables. Buprenorphine doses up to $16 \mathrm{mg}$ were considered as low dose and higher values as high. This was done because the dose-dependence of buprenorphine pharmacodynamics is not linear [33]. BZD doses were considered as low if lower than $20 \mathrm{mg}$ and higher if $20 \mathrm{mg}$ or above. The number of prescribed psychoactive drugs, other than OST or BZD drug, was considered as low up to one drug, and high if two or more other drugs. Duration of OST was considered as short if between six and twelve months, and long if above this. Substance abuse in the previous month was dichotomized as high vs. low frequency of abuse. Abstinence or substance abuse up to two days a week was considered as low-frequency substance abuse, and values above this as high-frequency substance abuse. This was based on findings showing that a mean three days of substance abuse a week is associated with a worsening of psychosocial and cognitive problems [35-37]. Substance abuse age of onset was considered as early onset up to 14 years of age, and as late onset age if 15 years of age or higher. This was based on findings showing that substance abuse onset before 15 years is especially hazardous to psychosocial and cognitive development [38]. Education was considered as low if no other than primary education had been completed, and as high if any secondary education had been completed. Homogeneity of error variance (homoscedasticity) was confirmed graphically by plotting the standardized residual against the predicted values. Independence of errors was checked using the DurbinWatson test. Normality of residuals was checked by normality plots and using the Shapiro-Wilk's test. Because our main interest was to examine drug treatment variables 
as predictors of cognitive performance, we employed multiple sequential/hierarchical linear regression analysis. First, the full model was examined as follows. Demographic variables, substance abuse variables, and the number of tests (one vs. more than one), were first entered into the model as control variables. Demographic variables included sex, level of education, and age if the test values were not age-corrected initially. Substance abuse variables included age of onset of substance abuse and frequency of substance abuse in the past month. Control variables were retained in the subsequent reduced model only if they gave a statistically significant $(p<0.05)$ contribution to the full model as a block or individually. The number of tests was also checked for the direction of association, with a positive association indicating a practice effect of repeated testing. Drug treatment variables included opioid drug type (buprenorphine vs. methadone), BZD treatment (yes vs. no), the number of psychoactive drugs (other than opioid or BZD drugs), and duration of OST. All drug treatment variables were entered sequentially into the reduced model. Unless otherwise stated, explained variance $\left(R^{2}\right)$ is reported as an adjusted value, and the regression coefficient as a standardized value (beta). All statistical analyses were done by SPSS statistical software, version 20.0, with the exception of effect size calculations, which were done by an effect size calculator devised by Durham University, UK [39]. Effect size estimations were corrected by Hedge's correction for sample size bias.

\section{Cognitive tests}

Attention was assessed by two tasks from the Test for Attentional Performance (TAP) [40]. In the Alertness task, the participant is instructed to respond to visual stimuli by pressing a response key as quickly as possible. The stimuli are presented without and with an auditory warning signal. The 'without' condition is a simple reaction time task reflecting tonic alertness. The 'withauditory-warning-signal' condition reflects both tonic and phasic alertness. Age corrected values were used in analyzing reaction time results.

Working memory was assessed by the Letter-Number Sequencing task from the Wechsler Memory Scale-III. In this test the participant is instructed to repeat letters and numbers in specific order [41]. Age corrected values were used.

Verbal memory was assessed by the Logical Memory from the Wechsler Memory Scale-III [41]. However, only immediate recall was tested and one story used. For those participants tested repeatedly a different story was given than previously. Visual memory was assessed by the Benton Visual Retention Test [42].

\section{Results}

\section{Group comparisons}

Buprenorphine-treated patients showed statistically significantly faster simple reaction times in comparison to methadone-treated ones (the 'without warning signal' condition of the alertness test; $(F(1,100)=7.54$, $p=0.028)$. No other significant differences emerged. (All test results shown as an Additional file 1).

\section{Predictors of attention performance}

When control variables were first entered into the full model they could predict only $1.3 \%$ of the performance variance $(2.8 \%$ in the sample) of the combined alertness measure. In contrast, drug treatment variables as a block could predict an additional $6.3 \%$ (9.7\% in the sample). The increment of drug treatment variables as a block significantly improved the model $(F(4,93)=2.59$, $p=0.041)$, but the full model remained statistically nonsignificant $(p=0.12)$. None of the individual predictors turned out to be significant in the full model. When the reduced model including only the drug treatment variables was tested, the OST drug group turned out to be the only significant predictor in the model (beta $=.20, t(97)=2.09$, $p=0.040)$. The reduced model was significant $\left(\mathrm{R}^{2}\right.$ $($ adjusted $)=.056, F(4,97)=2.51, p=0.047)$.

In order to examine the hypothesis that reaction times are predicted by different drug treatment variables in buprenorphine- vs. methadone-treated patients, the reduced model including drug treatment variables was used. As shown in Table 3, in the buprenorphine group, being on BZD drug treatment was the only significant predictor in the model. In the methadone group, the high number of other psychoactive drugs was the best and only significant predictor in the model. Adding methadone dose to the model made it significant, although the negative association of methadone dose was not independently significant.

\section{Predictors of working memory performance}

The full model including control variables predicted $8.2 \%$ of the variance $(16.4 \%$ in the sample). The model as a whole was significant $(F(8,93)=2.28, p=0.028)$. None of the control variables as a block or individually gave a significant contribution to the model. Consequently the control variables predicted a very low proportion of the variance $(-2.5 \%)$. In contrast, the drug treatment variables as a block significantly improved the full model $(F(4,93)=4.13, p=0.004)$ predicting $11.7 \%$ of the variance above the control variables. Therefore, the control variables were removed from the model. As shown in Table 4, treatment with a BZD drug was negatively associated with working memory performance while being more than one year in OST was positively 
Table 3 Hierarchical regression results for combined reaction times in the Alertness test by opioid drug group

\begin{tabular}{|c|c|c|c|c|}
\hline \multicolumn{5}{|l|}{ Buprenorphine-treated patients $(n=51)$} \\
\hline Predictors in the reduced model & Step1 Beta $(t \text {-test })^{a, b}$ & Step2 Beta ( $t$-test) & Step3 Beta (t-test) & Step4 Beta (t-test) \\
\hline \multicolumn{5}{|l|}{ Drug treatment variables } \\
\hline \multirow[t]{3}{*}{ BZD treatment (yes vs. no) } & .34 & .36 & .37 & .38 \\
\hline & $t(49)=2.51$ & $t(48)=2.64$ & $t(47)=2.60$ & $t(46)=2.60$ \\
\hline & $p=0.015^{*}$ & $p=0.011^{*}$ & $p=0.012^{*}$ & $p=0.013^{*}$ \\
\hline Buprenorphine dose (high vs. low) ${ }^{c}$ & & -.16 & -.17 & -.19 \\
\hline $\begin{array}{l}\text { The number of psychoactive drugs, other than } \\
\text { opioid or BZD (high vs. low) }\end{array}$ & & & .05 & .05 \\
\hline Duration of OST (long vs. short) ${ }^{\mathrm{e}}$ & & & & -.05 \\
\hline $\mathrm{R}^{2}$ (adjusted) & .096 & .103 & .084 & .069 \\
\hline \multirow[t]{2}{*}{ Model (ANOVA) } & $F(1,49)=6.29$ & $F(2,48)=3.88$ & $F(3,47)=2.58$ & $p=0.12$ \\
\hline & $p=0.015^{*}$ & $p=0.027^{*}$ & $p=0.065 \#$ & \\
\hline Change (ANOVA) $^{a}$ & & $p=0.24$ & $p=0.76$ & $p=0.71$ \\
\hline \multicolumn{5}{|l|}{ Methadone-treated patients $(n=51)$} \\
\hline Predictors in the reduced model & Step1 Beta (t-test) $)^{a, b}$ & Step2 Beta ( $t$-test) & Step ${ }^{f}$ Beta ( $t$-test) & \\
\hline \multicolumn{5}{|l|}{ Drug treatment variables } \\
\hline \multirow{3}{*}{$\begin{array}{l}\text { The number of psychoactive drugs, other than } \\
\text { opioid or BZD (high vs. low) }\end{array}$} & $.27 \#$ & $.30 *$ & $.31 *$ & \\
\hline & $t(49)=1.92$ & $t(48)=2.21$ & $t(47)=2.09$ & \\
\hline & $p=0.060 \#$ & $p=0.032^{*}$ & $p=0.042^{*}$ & \\
\hline \multirow[t]{4}{*}{ Methadone dose BZD treatment (yes vs. no) } & & $.26 \#$ & $.26 \#$ & \\
\hline & & $t(48)=1.88$ & $t(47)=1.86$ & \\
\hline & & $p=0.066 \#$ & $p=0.069 \#$ & \\
\hline & & & -.02 & \\
\hline $\mathrm{R}^{2}$ (adjusted) & .051 & .098 & .073 & \\
\hline \multirow[t]{2}{*}{ Model (ANOVA) ${ }^{a}$} & $F(1,49)=3.71$ & $F(2,48)=3.72$ & $F(3,47)=2.43$ & \\
\hline & $p=0.060 \#$ & $p=0.032^{*}$ & $p=0.077 \#$ & \\
\hline Change (ANOVA) ${ }^{a}$ & & $0.066 \#$ & 0.90 & \\
\hline
\end{tabular}

Only $p$-value shown when $p \geq 0.10$.

${ }^{b}$ Signs of beta values are reversed so that positive values refer to slowing of reaction times.

${ }^{c}$ Considered as low up to $16 \mathrm{mg}$.

${ }^{\mathrm{d} C}$ Considered as low up to one drug.

${ }^{\mathrm{e}}$ Considered as short when between six and twelve months.

'Step 4 is not shown because 'the duration of OST' variable correlated strongly (.61) with methadone dose producing a multicollinearity condition, and on a theoretical basis it was excluded from the analyses.

${ }^{*} p<0.05 . \# p<0.10$.

associated with working memory performance. The BZD drug treatment effect was significant but the duration of the treatment effect only approached significance. Finally, the predictive power of the drug treatment variables including the BZD variables (type or dose) on working memory performance was tested using the group including only patients with BZD in their drug regimen $(n=75)$. However, this model had very low predictive power on working memory $(-0.6 \%)$ and was statistically non-significant $(p=0.48)$.

\section{Predictors of memory performance}

When repeated testing was entered as the first variable of the full model, it was significantly associated with verbal memory performance $($ beta $=.36, t(93)=3.49$, $p=0.0007)$. Therefore, in order to eliminate the significant effect of repeated testing from the model, a model including only patients tested once was formed $(\mathrm{n}=74)$. Because demographic variables had minimal effect in the initial full model (data not shown), this block was dropped from the next model. Thus, the model included substance abuse variables and drug treatment variables. Because age of onset of substance abuse (early vs. late) showed a non-significant effect in the model, it was dropped from the final model. As shown in Table 5, high-frequency substance abuse and a high number of other psychoactive drugs (other than opioid or BZD drug) were the only individual 
Table 4 Hierarchical regression results for working memory $(n=102)$

\begin{tabular}{|c|c|c|c|c|}
\hline Predictors in the reduced model & $\begin{array}{l}\text { Step } 1 \text { Beta } \\
(t \text {-test })^{\mathrm{a}}\end{array}$ & $\begin{array}{l}\text { Step } 2 \text { Beta } \\
\text { (t-test) }\end{array}$ & $\begin{array}{l}\text { Step } 3 \text { Beta } \\
\text { ( } t \text {-test) }\end{array}$ & $\begin{array}{l}\text { Step } 4 \text { Beta } \\
\text { (t-test) }\end{array}$ \\
\hline \multicolumn{5}{|l|}{ Drug treatment variables } \\
\hline \multirow[t]{3}{*}{ BZD treatment (yes vs. no) } & -.34 & -.30 & -.28 & -.28 \\
\hline & $t(100)=3.56$ & $t(99)=3.14$ & $t(98)=2.83$ & $t(97)=2.81$ \\
\hline & $p=0.0006^{* * *}$ & $p=0.002 * *$ & $p=0.006^{*}$ & $p=0.006 *$ \\
\hline \multirow[t]{3}{*}{ Duration of OST (long vs. short) ${ }^{\text {b }}$} & & .17 & .17 & .16 \\
\hline & & $t(99)=1.81$ & $t(98)=1.72$ & $t(97)=1.69$ \\
\hline & & $p=0.074 \#$ & $p=0.088 \#$ & $p=0.094 \#$ \\
\hline The number of psychoactive drugs, other than opioid or BZD (high vs. low) ${ }^{c}$ & & & -.06 & .07 \\
\hline OST drug type (buprenorphine vs. methadone) & & & & -.03 \\
\hline$R^{2}$ (adjusted) & .104 & .124 & .119 & .100 \\
\hline \multirow[t]{2}{*}{ Model (ANOVA) ${ }^{a}$} & $F(1,100)=12.68$ & $F(2,99)=8.12$ & $F(3,98)=5.52$ & $F(4,97)=4.12$ \\
\hline & $p=0.0006^{* * *}$ & $p=0.0006^{* * *}$ & $p=0.002^{* *}$ & $p=0.004^{* *}$ \\
\hline \multirow[t]{2}{*}{ Change (ANOVA) } & & $F(1,99)=3.26$ & & \\
\hline & & $p=0.074 \#$ & $p=0.52$ & $p=0.76$ \\
\hline
\end{tabular}

anly $p$-value shown when $p \geq 0.10$.

${ }^{\mathrm{b} C o n s i d e r e d}$ as short when between six and twelve months.

${ }^{c}$ Considered as low up to one drug.

${ }^{* * *} p<0.00$. ${ }^{* *} p<0.01$. ${ }^{*} p<0.05$. \#p $<0.10$.

significant predictors of verbal memory performance, both of which were associated negatively with verbal memory performance.

The full or reduced model predicting visual memory showed only low and non-significant values for all predictors. Thus, the predictive power of the models remained non-significant $(p=0.33$ and $p=0.85$, respectively).

\section{Discussion}

The aim of the study was to examine the predictive power of drug treatment variables on specific cognitive

Table 5 Hierarchical regression results for verbal memory $(n=74)$

\begin{tabular}{|c|c|c|c|c|c|}
\hline Predictors in the reduced model & $\begin{array}{l}\text { Step } 1 \text { Beta } \\
{\text { ( } t \text {-test })^{\mathrm{a}}}\end{array}$ & $\begin{array}{l}\text { Step } 2 \text { Beta } \\
\text { ( } t \text {-test) }\end{array}$ & $\begin{array}{l}\text { Step } 3 \text { Beta } \\
\text { ( } t \text {-test) }\end{array}$ & $\begin{array}{l}\text { Step } 4 \text { Beta } \\
\text { (t-test) }\end{array}$ & $\begin{array}{l}\text { Step } 5 \text { Beta } \\
\text { (t-test) }\end{array}$ \\
\hline \multicolumn{6}{|l|}{ Substance abuse variable } \\
\hline \multirow{3}{*}{$\begin{array}{l}\text { Frequency of the previous month substance } \\
\text { abuse (high vs. low) }\end{array}$} & -.35 & $-.34 * *$ & $-.36 * *$ & $-.35 * *$ & $-.36^{* *}$ \\
\hline & $t(72)=3.17$ & $t(71)=3.24$ & $t(70)=3.34$ & $t(69)=3.22$ & $t(68)=3.15$ \\
\hline & $p=0.002^{* *}$ & $p=0.002^{* *}$ & $p=0.0013^{* *}$ & $p=0.002^{* *}$ & $p=0.002^{* *}$ \\
\hline \multirow{4}{*}{$\begin{array}{l}\text { Drug treatment variables } \\
\text { The number of psychoactive drugs, other than } \\
\text { opioid or BZD (high vs. low) }\end{array}$} & & & & & \\
\hline & & -.32 & -.35 & -.35 & $-.35 * *$ \\
\hline & & $t(71)=3.06$ & $t(70)=3.15$ & $t(69)=3.13$ & $t 68)=2.99$ \\
\hline & & $p=0.003^{* *}$ & $p=0.002^{* *}$ & $p=0.003^{* *}$ & $p=0.004^{* *}$ \\
\hline BZD treatment (yes vs. no) & & & .10 & .10 & 10 \\
\hline OST drug type (buprenorphine vs. methadone) & & & & -.03 & -.03 \\
\hline Duration of OST (long vs. short) $^{d}$ & & & & & .01 \\
\hline $\mathrm{R}^{2}$ (adjusted) & .110 & .203 & .199 & .189 & .177 \\
\hline \multirow[t]{2}{*}{ Model (ANOVA) } & $F(1,72)=10.02$ & $F(2,71)=10.28$ & $F(3,70)=7.06$ & $F(4,69)=5.24$ & $F(5,68)=4.14$ \\
\hline & $p=0.002^{* *}$ & $p=0.0001^{* * *}$ & $p=0.0003^{* * *}$ & $p=0.001^{* * *}$ & $p=0.002 *$ \\
\hline \multirow[t]{2}{*}{ Change (ANOVA) } & & $F(1,71)=9.37$ & & & \\
\hline & & $p=0.003^{* *}$ & $p=0.40$ & $p=0.79$ & $p=0.91$ \\
\hline
\end{tabular}

anly $p$-value shown when $p \geq 0.10$.

${ }^{\mathrm{b}}$ Considered as high when three or more days a week. Alcohol use was taken into account if it was at least mean weekly 16 portions (12 g) for females and

24 portions for males or binge drinking occurred on any day.

${ }^{\mathrm{c}}$ Considered as low up to one drug.

${ }^{\mathrm{d} C o n s i d e r e d ~ a s ~ s h o r t ~ w h e n ~ b e t w e e n ~ s i x ~ a n d ~ t w e l v e ~ m o n t h s . ~}$

${ }^{* * *} p<0.001$. ${ }^{* *} p<0.01$. ${ }^{*} p<0.05$. $\# p<0.10$. 
performance measures in multidrug-treated opioiddependent patients. Also, we were interested in finding out which of the possible significant associations turn out as hypothesized. All patients had been in OST for at least six months, and there were no major changes in their drug regimen within the last week prior to the study. Being on methadone-treatment predicted a rather low, though statistically significant proportion (about $5 \%$ ) of attention performance as measured by combined reaction times in alertness tests. When opioid drug groups were analyzed separately about $10 \%$ of attention performance variance could be explained in both groups, but the predictors were different. Being on BZD drug treatment predicted about $10 \%$ of working memory performance. Having more than one other psychoactive drug (than an opioid or BZD drug) was negatively associated with verbal memory performance. Also, recent high-frequency substance abuse was negatively associated with verbal memory performance. Together these factors predicted about $20 \%$ of verbal memory performance variance.

\section{Drug treatment variables as predictors of attention performance}

In buprenorphine patients co-treatment with a BZD drug was negatively associated with attention performance, but buprenorphine dose had no significant effect. This is in line with an experimental study showing that BZD diazepam in combination with buprenorphine affects negatively on reaction time, and the effect is independent of the buprenorphine dose administered [21]. In methadone patients the interpretation is more complex. The highest predictor of slower reaction time in methadone patients was treatment with more than one other psychoactive drug than methadone or BZD (beta .31). As hypothesized, there was a positive slope between methadone dose and the combined reaction time (.26) among methadone-treated patients. It is known that rapid elevation of methadone dose reduces peripheral blood oxygen saturation even among patients highly tolerant to methadone [43]. Oxygen saturation reduction has been associated with specific reaction time deficit with relative sparing of other cognitive functions [44]. Specific to methadone it has been shown by Lintzeris et al. that when a higher than normal (150\%) dose of methadone is given to methadone-treated opioiddependent patients, reductions in oxygen saturation and reaction time can be detected [21]. In sum, our results give support to our hypotheses that among buprenorphine patients, co-treatment with a BZD drug is associated negatively with attention performance. Methadone treatment, especially when done together with other psychoactive drugs, can be negatively associated with attention performance. Of note here is the timing of the possible opioid agonist effects: the drug plasma concentration peaks between $0.5-4 \mathrm{~h}$ after the dose for buprenorphine and 2-6 h for methadone [31,45-47].

\section{Drug treatment variables as predictors of working memory performance}

Our hypothesis of an advantage for buprenorphine in working performance was not supported by the analyses. Instead, treatment with a BZD drug was negatively associated with working memory performance (Table 4). When we analyzed the possible associations of BZD drug type or dose, no significant associations were found, and the model had very low predictive power. Thus, we could not link the working performance with BZD parameters. According to the meta-analysis, BZDs in general have small or medium sized negative effects on working memory functioning as measured by Cohen's d [24]. Although diazepam and oxazepam are probably the most widely used BZDs, few studies have examined their effects on a complex working memory measure like Letter-Number Sequencing. One study found that $5 \mathrm{mg}$ of diazepam did not affect performance in the complex working memory measure, the n-back task, although it reduced frontal brain activation [48]. It is known that high BZD doses have a general sedative effect and thus have the potential to affect cognitive function, but the development of tolerance may outweigh these effects [49]. Notably, we observed that more than one year in OST was positively, although weakly associated with working memory performance (beta $=.16$ ). This observation is in line with our previous observation that working memory improves in buprenorphine patients between six and twelve months into OST [22].

\section{Drug treatment variables as predictors of memory performance}

The high number of other psychoactive drugs (than opioid and BZD) and recent high- frequency substance abuse together predicted $20 \%$ of immediate verbal memory performance variance as measured by a story recall task. There is some evidence that verbal memory is more sensitive than other cognitive domains to the negative effects of multiple psychoactive drugs. This observation, however, may be specific to elderly patients and anticholinergic drugs [50]. Even less is known about the possible memory effects of psychoactive drug burden (as measured by the number of drugs) in combination with opioid agonists. In our recent longitudinal study, both buprenorphine- and methadone-treated patients lagged behind healthy controls in verbal memory performance as measured by story recall [22]. Surprisingly, when we extended the sample in the second part of our earlier study, the difference to healthy controls disappeared. Also, the correlation between the number of psychoactive 
drugs and verbal memory was positive, not negative, as in the current study. In sum, although our finding of a negative verbal memory effect of more than one psychoactive drug is in concert with our hypothesis, the specificity of this finding cannot be shown with our data. The finding that recent high-frequency substance abuse predicted poor verbal memory is in accordance with studies showing that recent frequent substance abuse impairs verbal memory performance $[51,52]$.

\section{Implications}

The results of this study suggest that cognitive impairment in opioid-dependent patients is more common when the patient is prescribed additional psychoactive drugs. It is also likely, although not confirmed by our study, that at least long-term BZD medication independently predicts cognitive impairment among multidrugtreated opioid-dependent patients. Fortunately, during OST many patients become more open to discussion about medication side-effects. Patients may agree that slower reaction times, associated in our study with comedication differently in buprenorphine- vs. methadonetreated patients, can be disadvantageous in vehicle driving and many sport activities. For instance there is evidence OST patients being disproportionately involved in road traffic crashes accidents [53,54]. Working memory deficits, associated in our study with BZD comedication, are known to impair reading comprehension, learning, and reasoning [55]. BZDs interfere with affective learning which is important in therapy [56]. Thus, combining BZD medication with psychological treatment may actually be detrimental to the long-term outcome of the treatment. The finding that one fifth of story recall performance variance was explained by two variables (high number of psychoactive drugs other than opioid or BZD drug; and high-frequency substance abuse in the previous month) is also relevant information. The optimal functioning of verbal memory is a useful resource in everyday life, work, or education [57]. All these facts may give the patient and prescriber a good reason to consider non-pharmacological treatment choices in place of polypharmacy. In some cases a realistic choice, for the time being, is to change cognitively harmful drugs like BZDs and tricyclic antidepressants for ones that are less harmful to cognition $[58,59]$.

\section{Limitations}

The distribution of the drug treatment variables, except opioid drug groups, was unplanned, and turned out to be highly skewed for some variables. As dichotomizations were used for these variables this reduces the statistical power of the analyses [60]. Therefore our findings about drug treatment effects are preliminary. Also, data about opioid and BZD doses may not be fully accurate, because drug screens do not detect extra doses of prescription drugs. Thus, our results do not confirm a causal association between drug treatment variables and cognitive performance. Patients with a higher number of prescribed drugs may have premorbid cognitive deficits that explain the associations found. On the other hand, longitudinal studies of patient groups other than OST patients have shown that discontinuation of a BZD drug regimen is followed by slow improvement in cognitive function and quality of life but no negative effects on sleep [61-64]. Our results support the idea that this could also be possible in opioid-dependent patients as well. There has been progress in the classification of psychoactive drugs by their interaction potential with buprenorphine or methadone [5,58] Alternatively, the recently formed drug burden index could be a promising tool for reducing the number of drug treatment variables in clinical studies [65]. These tools were found, however, to be unsuitable for our purposes. Negative cognitive effects of psychoactive drugs usually diminish during long-term use, and there may be differences in this between attention and memory effects [22,59,66,67]. If we had had data on length of drug use this would have been an important variable in analysing drug treatment effects. Our regression analyses were restricted only to the main effects of variables. Perhaps interactions between the variables could have explained more of the variation in cognitive performance. This was not considered appropriate given the high number of variables. Repeated testing of a third of patients is a potential confounder in the results, although after an interval of six months between testing times, as was the case in our study, the effects of repeated testing are trivial or non-existent for most measures [68,69]. In our study the verbal memory test, the Logical Memory test, was an exception, and this was taken into account in the analyses. Inclusion of psychiatric control variables, as used by Loeber et al. or Prosser et al. when studying cognitive performance in opioid-dependent patients, would probably have raised the predictive power of the analyses [70,71], and consequently the specificity of the findings.

\section{Conclusions}

While the causal direction of effects cannot be assured with these data, the results agree with the idea that specific prescription drug treatment variables may predict poor cognitive performance in OST patients. Improvement in quality of life, successful psychological treatment, and work or education participation are common goals in OST programs, each of which are associated with good cognitive functioning. Our results suggest that psychoactive polypharmacy may be contradictory to these goals. This should give treatment practitioners and 
policy makers one more reason to monitor the rationality of polypharmacy in OST.

\section{Additional file}

\section{Additional file 1: Group comparisons of cognitive performances.}

\section{Competing interests}

Pekka Rapeli has given a paid lecture in training organized by Schering-

Plough, the former manufacturer of buprenorphine.

\section{Authors' contributions}

PR planned and performed the cognitive testing and statistical analyses. He wrote the first version of the manuscript and prepared the final manuscript. HA conceived the idea of the study and advised in manuscript preparation. HK participated in the design of the study and in manuscript preparation. CF carried out psychiatric investigations. All authors have read and accepted the final manuscript.

\section{Acknowledgements}

This work was funded by the National Institute of Health and Welfare, Finland (THL), the Yrjö Jahnsson Foundation, the Rauha and Jalmari Ahokas Foundation, the Emil Aaltonen Foundation, and the Psychiatry Department of Helsinki University Central Hospital. We thank Mikko Salaspuro, Veijo Virsu, and Kristian Wahlbeck for helpful comments during the study, Jari Lipsanen for statistical advice, and Mark Phillips for language editing. We are grateful to the patients and personnel of the clinics who participated in the study.

\section{Author details}

${ }^{1}$ Unit for Drug Dependence. Department of Psychiatry, Helsinki University Central Hospital, Helsinki, Finland. ${ }^{2}$ Department of Mental Health and Substance Abuse Services, National Institute for Health and Welfare (THL), Helsinki, Finland. ${ }^{3}$ Institute of Behavioural Sciences, University of Helsinki, Helsinki, Finland. ${ }^{4}$ Research Unit of Substance Abuse Medicine, University of Helsinki, Helsinki, Finland.

Received: 22 June 2012 Accepted: 23 October 2012

Published: 2 November 2012

\section{References}

1. United Nations Office on Drugs and Crime: 2007 World Drug Report. Vienna: United Nations Office on Drugs and Crime; 2007.

2. Brooner RK, King VL, Kidorf M, Schmidt CW, Bigelow GE: Psychiatric and substance use comorbidity among treatment-seeking opioid abusers. Arch Gen Psych 1997, 54:71-80.

3. Abou-Saleh MT, Janca A: The epidemiology of substance misuse and comorbid psychiatric disorders. Acta Neuropsychiatr 2004, 16:3-8.

4. Strain EC: Assessment and treatment of comorbid psychiatric disorders in opioid-dependent patients. Clin J Pain 2002, 18:S14-S27.

5. Lee HY, Li JH, Wu LT, Wu JS, Yen CF, Tang HP: Survey of methadone-drug interactions among patients of methadone maintenance treatment program in Taiwan. Subst Abuse Treat Prev Policy 2012, 7:11

6. Deering D, Horn J, Frampton CMA: Clients' perceptions of opioid substitution treatment: An input to improving the quality of treatment. Int J Ment Health Nurs 2012, 21:330-339.

7. Bramness JG, Kornor H: Benzodiazepine prescription for patients in opioid maintenance treatment in Norway. Drug Alcohol Depend 2007, 90:203-209

8. Eiroa-Orosa FJ, Haasen C, Verthein U, Dilg C, Schafer I, Reimer J: Benzodiazepine use among patients in heroin-assisted vs methadone maintenance treatment Findings of the German randomized controlled trial. Drug Alcohol Depend 2010, 112:226-233.

9. Schreiber S, Peles E, Adelson M: Association between improvement in depression, reduced benzodiazepine (BDZ) abuse, and increased psychotropic medication use in methadone maintenance treatment (MMT) patients. Drug Alcohol Depend 2008, 92:79-85.

10. Soyka M, Horak M, Dittert S, Kagerer S: Less driving impairment on buprenorphine than methadone in drug-dependent patients? J Neuropsychiatry Clin Neurosci 2001, 13:527-528.
11. Soyka M, Lieb M, Kagerer $S$, Zingg $C$, Koller $G$, Lehnert $P$, Limmer $C$, Kuefner $\mathrm{H}$, Hennig-Fast $\mathrm{K}$ : Cognitive functioning during methadone and buprenorphine treatment results of a randomized clinical trial. J Clin Psychopharmacol 2008, 28:699-703.

12. Giacomuzzi SM, Thill C, Riemer Y, Garber K, Ertl M: Buprenorphine-and methadone maintenance treatment: influence on aspects of cognitive and memory performance. Open Addict J 2008, 1:5-6.

13. Pirastu R, Fais R, Messina M, Bini V, Spiga S, Falconieri D, Diana M: Impaired decision-making in opiate-dependent subjects: effect of pharmacological therapies. Drug Alcohol Depend 2006, 83:163-168.

14. Soyka M, Limmer C, Lehnert R, Koller G, Martin G, Kuefner H, Kagerer S, Haberthuer A: A Comparison of Cognitive Function in Patients under Maintenance Treatment with Heroin, Methadone, or Buprenorphine and Healthy Controls: An Open Pilot Study. Am J Drug Alcohol Abuse 2011, 37:497-508.

15. De Maeyer J, Vanderplasschen W, Lammertyn J, van Nieuwenhuizen C, Sabbe B, Broekaert E: Current quality of life and its determinants among opiate-dependent individuals five years after starting methadone treatment. Qual Life Res 2011, 20:139-150.

16. Meier MH, Caspi A, Ambler A, Harrington H, Houts R, Keefe RSE, McDonald K, Ward A, Poulton R, Moffitt TE: Persistent cannabis users show neuropsychological decline from childhood to midlife. Proc Natl Acad Sci USA 2012, 109:1-8

17. McCowan C, Kidd B, Fahey T: Factors associated with mortality in Scottish patients receiving methadone in primary care: retrospective cohort study. BMJ 2009, 338:b2225.

18. Pil K, Raes E, Van den Neste T, Goessaert A-S, Veramme J, Verstraete A: Review of existing classification efforts. In DRUID Driving under the Influence of Drugs, Alcohol and Medicines Project co-funded by the European Commission within the Sixth Framework Programme (2002-2006). Belgium: Ghent University; 2008.

19. Rapeli P, Fabritius C, Kalska H, Alho H: Memory function in opioid-dependent patients treated with methadone or buprenorphine along with benzodiazepine: longitudinal change in comparison to healthy individuals. Subst Abuse Treat Prev Policy 2009, 4:6.

20. Lintzeris N, Mitchell TB, Bond A, Nestor L, Strang J: Interactions on mixing diazepam with methadone or buprenorphine in maintenance patients. J Clin Psychopharmacol 2006, 26:274-283.

21. Lintzeris N, Mitchell TB, Bond AJ, Nestor L, Strang J: Pharmacodynamics of diazepam co-administered with methadone or buprenorphine under high dose conditions in opioid dependent patients. Drug Alcohol Depend 2007, 91:187-194.

22. Rapeli P, Fabritius $\mathrm{C}$, Kalska $\mathrm{H}$, Alho $\mathrm{H}$ : Cognitive functioning in opioid-dependent patients treated with buprenorphine, methadone, and other psychoactive medications: stability and correlates. BMC Clin Pharmacol 2011, 11:13.

23. Spiga S, Lintas A, Diana M: Addiction and Cognitive Functions. In Drug Addiction: Research Frontiers and Treatment Advances. 1139th edition. Edited by Kuhar MJ. Oxford: Blackwell Publishing; 2008:299-306.

24. Barker MJ, Greenwood KM, Jackson M, Crowe SF: Cognitive effects of long-term benzodiazepine use: a meta-analysis. CNS Drugs 2004, 18:37-48.

25. Cancelli I, Beltrame M, Gigli GL, Valente M: Drugs with anticholinergic properties: cognitive and neuropsychiatric side-effects in elderly patients. Neurol Sci 2009, 30:87-92.

26. Chew ML, Mulsant BH, Pollock BG, Lehman ME, Greenspan A, Mahmoud RA, Kirshner MA, Sorisio DA, Bies RR, Gharabawi G: Anticholinergic activity of 107 medications commonly used by older adults. J Am Geriatr Soc 2008, 56:1333-1341

27. Meador KJ: Cognitive side effects of medications. Neurol Clin 1998, 16:141-155

28. Starr JM, McGurn B, Whiteman M, Pattie A, Whalley LJ, Deary IJ: Life long changes in cognitive ability are associated with prescribed medications in old age. Int J Geriatr Psychiatry 2004, 19:327-332.

29. First MB, Gibbon M, Spitzer R, Williams JB, Benjamin L: Structured Clinical Interview for DSM-IV, Axis I Disorders (SCID-I). New York: American Psychiatric Press; 1997.

30. Wechsler D: Wechsler Adult Intelligence Scale - Revised (WAIS-R). Finnish version. Helsinki: Psykologien Kustannus; 1993.

31. Chiang CN, Hawks RL: Pharmacokinetics of the combination tablet of buprenorphine and naloxone. Drug Alcohol Depend 2003, 70:S39-S47. 
32. Orman JS, Keating GM: Buprenorphine/Naloxone a review of its use in the treatment of opioid dependence. Drugs 2009, 69:577-607.

33. Harris DS, Mendelson JE, Lin ET, Upton RA, Jones RT: Pharmacokinetics and subjective effects of sublingual buprenorphine, alone or in combination with naloxone: lack of dose proportionality. Clin Pharmacokinet 2004, 43:329-340.

34. Nelson J, Chouinard G: Guidelines for the clinical use of benzodiazepines: pharmacokinetics, dependency, rebound and withdrawal. Can J Clin Pharmacol 1999, 6:69-83.

35. Nocon A, Wittchen HU, Pfister H, Zimmermann P, Lieb R: Dependence symptoms in young cannabis users? A prospective epidemiological study. J Psychiatr Res 2006, 40:394-403.

36. Shakeshaft AP, Bowman JA, Sanson-Fisher RW: A comparison of two retrospective measures of weekly alcohol consumption: diary and quantity/frequency index. Alcohol Alcohol 1999, 34:636-645.

37. Wadsworth EJK, Moss SC, Simpson SA, Smith AP: Cannabis use, cognitive performance and mood in a sample of workers. J Psychopharmacol 2006, 20:14-23.

38. Bava S, Tapert SF: Adolescent Brain Development and the Risk for Alcohol and Other Drug Problems. Neuropsychol Rev 2010, 20:398-413.

39. Effect Size Calculator. http://www.cemcentre.org/renderpage.asp? linkID=30325017.

40. Zimmermann P, Fimm B: Test for Attentional Performance (TAP). Herzogenrath: PsyTest; 1995.

41. Wechsler D: Wechler Memory Scale - Third Edtion. San Antonio, TX: The Psychological Corporation; 1997.

42. Benton A: The Revised Visual Retention Test. New York: Psychological Corporation; 1963.

43. Walker PW, Klein D, Kasza L: High dose methadone and ventricular arrhythmias: a report of three cases. Pain 2003, 103:321-324.

44. Gerard AB, McElroy MK, Taylor MJ, Grant I, Powell FL, Holverda S, Sentse N, West JB: Six percent oxygen enrichment of room air at simulated $5000 \mathrm{~m}$ altitude improves neuropsychological function. High Alt Med Biol 2000, 1:51-61.

45. Escher M, Daali Y, Chabert J, Hopfgartner G, Dayer P, Desmeules J: Pharmacokinetic and pharmacodynamic properties of buprenorphine after a single intravenous administration in healthy volunteers: A randomized, double-blind, placebo-controlled, crossover study. Clin Ther 2007, 29:1620-1631.

46. Dyer KR, White JM, Foster DJR, Bochner H, Menelaou A, Somogyi AA: The relationship between mood state and plasma methadone concentration in maintenance patients. J Clin Psychopharmacol 2001, 21:78-84.

47. Eap CB, Buclin T, Baumann P: Interindividual variability of the clinical pharmacokinetics of methadone - Implications for the treatment of opioid dependence. Clin Pharmacokinet 2002, 41:1153-1193.

48. Ragnehed M, Hakansson I, Nilsson M, Lundberg P, Soderfeldt B, Engstrom M: Influence of diazepam on clinically designed FMRI. J Neuropsychiatry Clin Neurosci 2007, 19:164-172.

49. Stewart SA: The effects of benzodiazepines on cognition. J Clin Psychiatry 2005, 66:9-13

50. Fortin MP, Rouch I, Dauphinot V, Gedeon C, Genthon S, Bonnefoy M, Krolak-Salmon P: Effects of Anticholinergic Drugs on Verbal Episodic Memory Function in the Elderly A Retrospective, Cross-Sectional Study. Drugs Aging 2011, 28:195-204.

51. Horner MD, Waid LR, Johnson DE, Latham PK, Anton RF: The relationship of cognitive functioning to amount of recent and lifetime alcohol consumption in outpatient alcoholics. Addict Behav 1999, 24:449-453.

52. Pope HG Jr, Gruber AJ, Hudson Jl, Huestis MA, Yurgelun-Todd D: Neuropsychological performance in long-term cannabis users. Arch Gen Psych 2001, 58:909-915.

53. Bramness JG, Skurtveit S, Morland J, Engeland A: An increased risk of motor vehicle accidents after prescription of methadone. Addiction 2012, 107:967-972.

54. Corsenac P, Lagarde E, Gadegbeku B, Delorme B, Tricotel A, Castot A, Moore $N$, Philip P, Laumon B, Orriols L: Road traffic crashes and prescribed methadone and buprenorphine: A french registry-based case-control study. Drug Alcohol Depend 2012, 123:91-97.

55. Baddeley A: Working memory: Looking back and looking forward. Nat Rev Neurosci 2003, 4:829-839.
56. Würz A, Sungur MZ: Combining Cognitive Behavioural Therapy and Pharmacotherapy in the Treatment of Anxiety Disorders: True Gains or False Hopes? Bulletin of Clinical Psychopharmacology 2009, 19:436-446.

57. Sunderland A: Do laboratory tests predict everyday memory? A neuropsychological study. J Verb Learn Verb Behav 1983, 22:341-357.

58. McCance-Katz EF, Sullivan LE, Nallani S: Drug interactions of clinical importance among the opioids, methadone and buprenorphine, and other frequently prescribed medications: a review. Am J Addict 2010, 19:4-16.

59. Stein RA, Strickland TL: A review of the neuropsychological effects of commonly used prescription medications. Arch Clin Neuropsychol 1998 13:259-284.

60. DeCoster J, Iselin AM, Gallucci M: A conceptual and empirical examination of justifications for dichotomization. Psychol Methods 2009, 14:349-366.

61. Kitajima R, Miyamoto S, Tenjin T, Ojima K, Ogino S, Miyake N, Fujiwara K, Funamoto Y, Arai J, Tsukahara S, et al: Effects of tapering of long-term benzodiazepines on cognitive function in patients with schizophrenia receiving a second-generation antipsychotic. Prog Neuropsychopharmacol Biol Psychiatry 2012, 36:300-306.

62. Kilic C, Curran HV, Noshirvani H, Marks IM, Basoglu M: Long-term effects of alprazolam on memory: a 3-5 year follow-up of agoraphobia/panic patients. Psychol Med 1999, 29:225-231.

63. Curran HV, Collins R, Fletcher S, Kee SCY, Woods B, lliffe S: Older adults and withdrawal from benzodiazepine hypnotics in general practice: effects on cognitive function, sleep, mood and quality of life. Psychol Med 2003, 33:1223-1237.

64. Barker MJ, Greenwood KM, Jackson M, Crowe SF: Persistence of cognitive effects after withdrawal from long-term benzodiazepine use: a meta-analysis. Arch Clin Neuropsychol 2004, 19:437-454

65. Hanlon JT, Rubin SM, Shorr Rl, et al: A drug burden index to define the functional burden of medications in older people. Arch Intern Med 2007, 167:781-787.

66. Rickels K, Lucki I, Schweizer E, Garcia-Espana F, Case WG: Psychomotor performance of long-term benzodiazepine users before, during, and after benzodiazepine discontinuation. J Clin Psychopharmacol 1999, 19:107-113

67. Gruber SA, Silveri MM, Renshaw PF, Tzilos GK, Pollack M, Kaufman MJ, Yurgelun-Todd DA: Methadone maintenance improves cognitive performance after two months of treatment. Exp Clinic Psychopharmacol 2006, 14:157-164

68. Bartels C, Wegrzyn M, Wiedl A, Ackermann V, Ehrenreich H: Practice effects in healthy adults: a longitudinal study on frequent repetitive cognitive testing. BMC Neurosci 2010, 11:118.

69. Basso MR, Carona FD, Lowery N, Axelrod BN: Practice effects on the WAIS-III across 3- and 6-month Intervals. Clin Neuropsychol 2002, 16:57-63.

70. Prosser J, Eisenberg D, Davey E, Steinfeld M, Cohen L, London E, Galynker : Character pathology and neuropsychological test performance in remitted opiate dependence. Subst Abuse Treat Prev Policy 2008, 3:23.

71. Loeber S, Nakovics H, Kniest A, Kiefer F, Mann K, Croissant B: Factors affecting cognitive function of opiate-dependent patients. Drug Alcohol Depend 2012, 120:81-87.

doi:10.1186/1747-597X-7-45

Cite this article as: Rapeli et al:: Do drug treatment variables predict cognitive performance in multidrug-treated opioid-dependent patients? A regression analysis study. Substance Abuse Treatment, Prevention, and Policy 2012 7:45. 